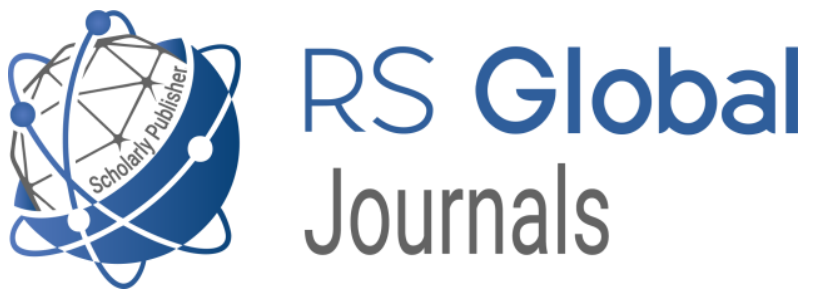

Scholarly Publisher

RS Global Sp. z O.O.

ISNI: 0000000484952390

Dolna 17, Warsaw, Poland 00-773

Tel: +48226022703

Email: editorial_office@rsglobal.pl

JOURNAL International Journal of Innovative Technologies in Social Science

p-ISSN

$2544-9338$

e-ISSN

2544-9435

PUBLISHER

RS Global Sp. z O.O., Poland

ARTICLE TITLE

COMPONENTS OF THE TRAINING PROGRAM FOR EDUCATORS WORKING ON THE DEVELOPMENT OF THE MATHEMATICALLY GIFTED STUDENTS POTENTIAL

$\operatorname{AUTHOR}(\mathbf{S})$

ARTICLE INFO

DOI

RECEIVED

ACCEPTED

PUBLISHED

LICENSE
Natalia Bonchuk

Natalia Bonchuk. (2021) Components of the Training Program for Educators Working on the Development of the Mathematically Gifted Students Potential. International Journal of Innovative Technologies in Social Science. 2(30). doi: 10.31435/rsglobal_ijitss/30062021/7624 https://doi.org/10.31435/rsglobal_ijitss/30062021/7624

02 May 2021

14 June 2021

18 June 2021

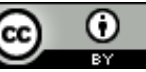

This work is licensed under a Creative Commons Attribution

4.0 International License.

(C) The author(s) 2021. This publication is an open access article. 


\title{
COMPONENTS OF THE TRAINING PROGRAM FOR EDUCATORS WORKING ON THE DEVELOPMENT OF THE MATHEMATICALLY GIFTED STUDENTS POTENTIAL
}

\author{
Natalia Bonchuk, Ph.D. student, Taras Shevchenko National University of Kyiv, Ukraine \\ DOI: https://doi.org/10.31435/rsglobal_ijitss/30062021/7624
}

\section{ARTICLE INFO}

Received 02 May 2021

Accepted 14 June 2021

Published 18 June 2021

\section{KEYWORDS}

mathematical talent, gifted student, advanced training, online training, interactive methods.

\begin{abstract}
The article is devoted to the formation and improvement of competencies of teachers and psychologists of secondary schools to identify and develop mathematically gifted students. It has been identified the components of the training program of basic competencies that psychologists and subject teachers must have to recognize and develop mathematical talent. The results of an empirical study of an educational project are online training for educators to deepen their theoretical knowledge of mathematical talent and the development of practical skills of organizing the educational process for students with a high level of ability in the field of exact sciences. It was found that training in the development of competencies is an effective way to improve the skills of teachers to understand the essence of talent, the peculiarities of its detection in students, prevention of loss of potential, development of individual educational trajectories, use of new learning technologies and ways to develop personal skills.
\end{abstract}

Citation: Natalia Bonchuk. (2021) Components of the Training Program for Educators Working on the Development of the Mathematically Gifted Students Potential. International Journal of Innovative Technologies in Social Science. 2(30). doi: 10.31435/rsglobal_ijitss/30062021/7624

Copyright: (C) 2021 Natalia Bonchuk. This is an open-access article distributed under the terms of the Creative Commons Attribution License (CC BY). The use, distribution or reproduction in other forums is permitted, provided the original author(s) or licensor are credited and that the original publication in this journal is cited, in accordance with accepted academic practice. No use, distribution or reproduction is permitted which does not comply with these terms.

Formulation of the problem. The rapid development of new technologies opens new prospects for teaching categories of students that require special attention from teachers who care for them. One such category of students is mathematically gifted. Historically, children who have an extremely high level of mathematical abilities had the opportunity to improve them in specialized schools, but not everyone entered there. There has always been and still is a significant proportion of those who did not get there for various reasons (at the discretion of the parents, or because of the remoteness of the village where the child lives from a specialized school). Modern life is based on high technologies, which makes it possible to overcome these limitations and develop the abilities of mathematically gifted children without being tied to a specific area and educational institution, which has teachers with appropriate qualifications. Also, the rapid development of Internet technologies provides an opportunity to develop mathematical talent for children from remote areas and villages, and, very importantly - creates opportunities for continuous personal and professional development of mathematics teachers and psychologists in the field, allowing them to master the necessary competencies to teach gifted students directly in the conditions of comprehensive school.

Thus, today there is an urgent problem of thorough training of subject teachers and psychologists, which is aimed at identifying, developing, and revealing the potential of mathematically gifted students. It is a pity that in our country far too little attention has been paid to proper training of specialists, who encounter mathematical giftedness in their work from time to time, but have not been trained to discern it or work to develop the skills of the gifted person. This can be explained by the fact that teacher training universities and institutes of post-graduate pedagogical education lack specialized courses focused on the psychology of giftedness, methods of its identification, specifics of developing and teaching such children. Against the background of the mathematical education crisis observed in our country, such competencies 
are important for educators as many students with a high level of abilities and giftedness, including mathematical giftedness, receive no proper attention and gradually lose their potential. This happens because abilities are either associated with general academic success rates or ignored as a subject matter of a teacher's or a psychologist's specific professional interest and an applied field of their professional duties.

In light of the above, we believe that teachers need appropriate theoretical and practical training aimed at developing skills to work with gifted and talented children. In our opinion, one of the effective ways to improve the level of qualification of teachers today is to develop interactive training programs that will help spread the necessary competencies to a wider cohort of educators without being tied to the place of residence and work. Training programs allow a wide range of professionals to acquire the necessary knowledge for free and remotely, representing a powerful global trend in modern education.

In the report to UNESCO of the International Commission on Education for the $21^{\text {st }}$ Century titled "Learning: the Treasure Within" (1997), distance learning is defined as the most prospective area of applying information and communications technology. At the UNESCO World Conference on Higher Education (Paris, 1998), it was emphasized that "distance learning and new information and communications technology provide access to education..." Post-graduate education for adults is a continuous process of a professional's improvement and modern technology makes it possible to learn online without deterioration of the quality of teaching and learning materials. As regards digital trends, futurologists foresee that the future of education relies on gamification as well as virtual and augmented reality.

Online learning or e-learning means learning involving the use of multimedia and Internet technology. This is presently the commonest form of distance learning continuously widening over the last 13 years. Online learning has been recently ahead of the traditional intramural form of learning in some respects. Distance learning perfectly supplements the traditional methods of upgrading qualification and is an alternative in some cases, which permits an educator not to disrupt the process of self-development and self-education in the fast developing circumstances of contemporary life. Pearson initiated a study comparing the results of learning in traditional and online schools of Mathematics and English in the USA. This is one of the most advanced countries when it comes to distance school learning as these practices have been used there since the 2000s. The study results helped researchers conclude that the efficiency of learning in an online school is no lower than that in a traditional one. The development and implementation of modern interactive courses to improve the skills of educators, opportunities to attract their wide audience, the convenience and accessibility of multimedia tools for adult learning as an element of continuing education is the issue of this article.

Distance learning programs, of course, have many positive aspects. They are focused on improving learning skills, on continuing education as a social trend, effectively implementing the modern model of "lifelong learning". Flexible organization of training during classes (the ability to choose the course, the theme of independent work, how to perform tasks), with a certain time frame, allows each student to move along their educational route. The use of modern educational technologies in the construction of courses (for example, the development of critical thinking, focus on project technology, etc.) makes the learning process personal and activity-oriented, making the program participant feel like an active individual of the educational process. Thus, interactive learning allows a specialist (a subject teacher or a psychologist of a secondary school) to improve their level of knowledge, to form a willingness to independently creatively designed individual educational programs, taking into account specific educational needs; to design the educational environment following modern requirements through available information technology.

The purpose of the article is to present the results of the experimental interactive training course on the theory of giftedness and the development of practical skills of teaching and developing students with a high level of mathematical abilities and giftedness in the framework of in-service training for subject teachers and school psychologists.

Analysis of researches and publications. Creating the training program "Psychology of Mathematical Giftedness for Teachers and School Psychologists", we were guided by the following guidelines. Successful work with gifted children requires knowledge of the nature of giftedness (in particular, mathematical) as a rare mental phenomenon. In 1966, V.A. Krutetsky emphasized that mathematical talent is a complex system of mental formation. Students especially gifted in mathematics are characterized by a peculiar mathematical orientation of the mind - the tendency to perceive many phenomena through the prism of mathematical relations, to realize them in terms of logical and mathematical categories. The main characteristics of mathematically gifted students: the ability to think logically (the ability to think in mathematical symbols); ability to quickly generalize mathematical 
objects, relationships, and actions; mathematical memory (generalized memory for mathematical relations, schemes of reasoning and evidence, methods of solving problems and principles of approach to them). Working with mathematically gifted students requires a high level of qualification of a teacher and a school psychologist and their thorough knowledge of the principles of the psychology of giftedness.

We also believe that professionals should have knowledge of the recognition of giftedness (especially partial or hidden), have an understanding of the peculiarities of the manifestation of giftedness in each age, have an idea of the difficulties faced by mathematically gifted children in socialization.

Besides, professionals need to understand the main reasons for the decline of the abilities of a mathematically gifted student, there are many such reasons. The specialist faces the task of a creative approach in solving an atypical task of maintaining the motivation of the child and the family members if there is a threat of loss of talent due to the unfavorable socio-cultural environment in which such a child is brought up; the psychological and financial difficulties of the family or the local community where a student is growing up; some personal characteristics of gifted children, including accentuation or deviation. A separate problem is also the impossibility of building an individual educational and developmental trajectory of mathematical abilities due to lack of relevant teachers` skills, the ability to work only for the general audience, ignoring the individual educational needs of the gifted student. At the same time, it does not depend on whether the school is rural or in a big city: in a large school, the probability of "seeing" and not noticing a child's talent may be even greater.

So, as already mentioned, subject teachers without special training often cannot identify gifted children, do not know their psychological characteristics; are not ready to work with them. It happens that teachers, faced with a gifted child with a difficult character (and this is not uncommon), show indifference to its problems, in some cases - hostility and even animosity, because gifted students can pose a threat to the authority of teachers; Sometimes such teachers often use the tactic of quantifying tasks for gifted children, rather than changing them qualitatively (N.S. Leites, 1996).

In their works, researchers O.M. Matiushkina, O.I. Savenkova, O.L. Yakovlieva and others emphasize that an educator of gifted children must be ready to develop efficient, flexible, and individualized programs; create a warm and emotionally safe climate within a class; provide students with the timely, adequate, and informative feedback; use various (often nonstandard) learning technologies.

According to A. K. Markova, working with gifted children requires the following components from a school team of teachers: 1) a professional and individual attitude; 2) a comprehensive nature of teachers' education; 3) creation of a system of consultations and trainings for teachers aimed at developing skills of self-knowledge, self-control, and self-development; 4) provision of special psychological and pedagogical conditions supposed to take into account the advanced psychological and pedagogical experience in working with gifted children, multi-faceted experience sharing to develop professional skills; 5) development of a creative and free educational and development atmosphere of learning at various levels and areas of professional activities (primary school teachers, subject teachers, special education teachers, school psychologists, and also school administration representatives, etc.) [3].

The issues of introducing interactive educational methods for adults have been considered by V.I. Hrytsenko, I.P. Bolodurina, V.V. Borshcheva, V.S. Kashparova, V.V. Kolos, S.P. Kudriavtseva, H.V. Mozhayeva, S.V. Nilova, V.Yu. Sinytsyn, S.O. Sysoyeva, T.V. Yakovenko, and others.

According to Yakovenko (2012), during the interactive courses, there is a binary learning effect: the educational nature is not only the content of the course but also the process of working remotely, which contributes to the development of the teacher's competences:

- skills in working with a personal computer, office programs, and the Internet; formation of general and specialized skills in working with information resources of various types and formats;

- acquaintance with the means and technologies supporting individual and group educational activity in the ICT-saturated environment;

- use of modern means of communication (communication via the Internet, audio and video conferences, etc.);

- formation of skills in the field of e-learning and self-education with the help of IT tools;

- formation of basic knowledge and skills in the organization of the educational process with the use of IT tools;

- development of students' skills of critical thinking when working with information resources.

Setting objectives. The task of identifying and developing mathematical talent has been and remains completely unsolved throughout the world. Early diagnosis, selection, the presence of specialized schools with a mathematical bias, as well as mathematical competitions and Olympiads do not save the situation, as many gifted students from different parts of the country are still often left 
without proper psychological and pedagogical support. The rapid development of online learning has an impact on education: today we can note a wide selection of various e-courses aimed at developing such narrow professional competencies as the psychology of the gifted learning process. Due to their convenience and accessibility, training programs are now an effective alternative to full-time refresher courses. Online learning can eliminate many barriers: geographical, physical, financial. However, we believe that today such training programs, especially for educators, are still insufficient, and in the psychological and pedagogical literature, there is a lack of work on the development and implementation of interactive educational projects for teachers and school psychologists. Consideration of these problems, as well as prospects for their solution, is the task of this study.

Presentation of the main research material. In order to improve the skills of educators, deepen the competence of those interested in working with mathematically gifted children, we have developed and offered an interactive online training program "Psychology of mathematical giftedness for teachers and school psychologists", which aims to increase competence in working with gifted students.

The program of interactive training of teachers on the issues of identification and development of mathematical talent of students is designed for 30 hours and includes the following sections:

a) Block 1. "Mathematical talent as a phenomenon. Psychophysiology, cognitive processes, and psychological features of a mathematically gifted child.

This thematic block of training is devoted to the theory of mathematical talent: the structure of mathematical talent as a complex psychological formation, as a deviation from the norm "up", as a phenomenon of dynamic, developing, experiencing latent periods, changing in different periods of ontogenesis. The eminent psychologist K. Jung noted in the middle of the last century that "a gifted person is from a biological point of view a deviation from the average norm." The question of the interrelation of cognitive abilities and typological features is considered. Features of perception, attention, memory, thinking of mathematically gifted children. The speed of the formation of the visual image. Concentration and distribution of attention depending on the type of nervous system. Psychological features of mathematically gifted children.

b) Block 2. "Strategies for recognition and identification of mathematical talent. Partial mathematical talent".

In this block, the participants study the methods and tools for identifying mathematical talent (tests, questionnaires, tasks, observations, interviews. Emphasis on understanding partial (partial) talent and the difficulty of its identification. Ways of its development. Of the autistic spectrum, giftedness is most often associated with Asperger's syndrome, which is characterized by milder manifestations of communication deficits along with normal language development and preserved intelligence.

After watching Zoom-video lectures on the theory of giftedness and acquaintance with the relevant literature, the participants did their homework, which consisted of project activities preparing a newsletter for parents of gifted children.

c) Block 3. "Creating individual educational trajectories for a gifted child".

How to help a gifted student regulate their learning. Problems and technologies of construction of a separate educational trajectory of a gifted student in the conditions of a secondary school. Techniques of educational coaching of gifted people, basics of mentoring. The block of the course "Creation of individual educational trajectories for a gifted child" involves mastering the theory and practice of building an individual educational and developmental program for a mathematically gifted student in the "normal" class of the secondary school. The Law of Ukraine "On Education" defines the individual educational trajectory as follows:

- Individual educational trajectory: a personal way of realizing the individual potential of a student formed by taking into account his/her abilities, interests, needs, motivation, capacities, and experience, based on the student's choice of education types, education forms and acquisition rates, subjects of educational activities and educational programs proposed by them, educational disciplines and their complexity level, methods and means of learning. An individual educational trajectory within an educational institution may be implemented through an individual educational plan;

- Individual educational plan: a document defining the order, form, and rate of the student's mastering of educational components of an educational program aimed at realizing his/her individual educational trajectory, developed by an educational institution in cooperation with the student, providing the required resources are available. This block of the course aims to strengthen the theoretical knowledge of teachers about the characteristics, methods, and models of individual educational trajectories for the mathematically gifted (features of a selection of individual methods and techniques of teaching, orientation in teaching materials for gifted students, specifics of the educational process, 
avoidance of standard teaching procedures, assessment of the level of knowledge of the gifted); as well as the section provides for the development of practical skills in homework (project work to build an individual educational trajectory for a student with implicit mathematical talent).

d) Block 4. "Age features of the development of mathematical talent." Mathematically gifted students from 5th to 11th grade go through a rapid process of growing up. It proceeds unevenly, differently at girls and boys, with the expressed individual features. The social situation of development is changing, the system of relations with significant others is being rebuilt, which inevitably affects the development of talent. In adolescence, the leading activity is communication with peers, however, learning does not disappear from the point of view of a gifted student. The development of self-awareness, a personal reflection is actively taking place. Sometimes learning and communication interfere with each other. How exactly does this happen and why? What to do with this school psychologist and teacher? How to make sure that both activities do not interfere with each other? How to rebuild relationships with gifted students who grow up so that they are productive in interaction with others and have a positive impact on the learning process? These questions will be presented from the standpoint of age psychology, useful for the work of the teacher. The reasons for possible bullying of gifted children are also considered, program participants gain knowledge about the components and structure of bullying. Children with giftedness and learning difficulties have an increased risk of communication problems, and they may find themselves in a kind of social isolation due to the fact that they do not find understanding among "ordinary" children (as well as often among children with learning difficulties without giftedness or among gifted children without learning difficulties), cannot properly build and maintain harmonious relationships with teachers and classmates (as well as with bosses and colleagues in adult life). The stages of organization of psychological and pedagogical measures to combat bullying of a gifted child in secondary school are considered. Participants of the program get acquainted with algorithms for building training in skills of regulation of emotions and behaviors for mathematically gifted students.

e) Block 5. "Countering the loss of mathematical talent. School climate ". The content of this block of the training program: harmful socio-cultural and gender stereotypes; motivation of the gifted student and his family members to develop the child's abilities. Methods of counteracting negative environmental factors at the risk of losing student motivation to develop mathematical talent.

Parental indifference inhibits the potential of the gifted because the child does not consider the passion for mathematics as one of the promising areas of its development and possible professionalization. Insufficient attention to the gifted child leads to the emergence of internal conflicts, which in turn causes changes in behavior: timidity, aggression, etc. (Shumakova, 2004).

Attention to the gender aspect: girls are most prone to the loss of talent due to the adverse effects of the social environment and existing false stereotypes.

Thus, this unit teaches teachers and psychologists to effectively combat the loss of giftedness systematic pedagogical and social work with the immediate environment of a mathematically gifted child at home and at school, the stability of motivation of the student, and his environment to develop abilities. A young person desperately needs the support of important people in his environment: how to help a teacher or psychologist, and what to do if the environment is not interested in it? Contact, communication, and collaboration techniques. The basics of goal-setting training for mathematically gifted students are considered.

School climate - the organization of educational and developmental space necessary for the realization of the potential of mathematical talent within the secondary school. Creating a comfortable emotional atmosphere, and at the same time stimulating, encourages the learning process. Creating a stimulating environment with the help of additional educational materials: posters, posters, collections, textbooks, etc. Ergonomics of the environment: giving students freedom of movement in the classroom. Ability to adapt forms of educational work according to individual educational needs, aptitudes, and abilities of students (flexibility).

f) Block 6. "Pedagogical skills in working with the gifted."

This block further analyses the role of teacher-mentor for a mathematically gifted student. Establishing boundaries and relationships. Teacher - as an object of psycho-emotional attachment of a mathematically gifted student. Competences of the teacher and his own creativity, development of abilities, continuous educational process. Mentoring for a mentor - where to look for him, how to share experiences with like-minded people.

The block "Pedagogical skills in working with mathematically gifted" is aimed at the formation and development of relevant skills in students. The theory and practice of pedagogical skills of a mathematics teacher for the gifted within the course is the development of professional 
competence, practice, ability to teach the subject, choosing ways of professional and personal development of teachers (models and structures), strengthening skills of creative use of modern methods of educational and cognitive activities. teaching ways to effectively interact with the teacher and the gifted student in the classroom, ways to increase the motivation of the gifted student to learning, to independent research, the development of flexibility of his thinking. In this section, as part of practical work, participants were asked to create a list and plan for the development of their own competencies that will help teachers work with gifted, as well as develop a detailed outline of a nonstandard lesson focused on teaching children with high abilities in mathematics.

g) Block 7. "Preparation of a gifted student for competitions, Olympiads". The block contains recommendations for the psychological and mathematical preparation of students for competitions and contests. This block is devoted to theoretical knowledge and practical skills of preparing a gifted student to participate in competitions, Olympiads in mathematics, tournaments, etc. The section examines ways to strengthen the potential of the student as a possible winner of the Mathematical Olympiad: students master the basic mathematical principles, important aspects of selecting tasks of increased complexity for training, increasing ways of creative problem solving, application of various organizational measures: extracurricular interactive learning, clubs and studios, summer schools. Particular attention is paid to the psychophysiological aspects of the selection of participants and the skills to help overcome anxiety and stress during competitions in gifted children. Homework requires drawing up a plan to prepare the participant for the Olympiad and selecting the most optimal training tasks, considering the level of his development and the characteristics of mathematical intelligence.

Each block of advanced training includes the following elements: a series of short educational video lectures on Zoom (10-15 minutes each), a list of specialized literature for self-study (articles, electronic abstracts), homework (creation of presentations, lesson plans, case studies), work in minigroups (role-playing games and discussion of cases in Zoom web rooms) and the presence of test control (each section is considered mastered if homework is done and at least $60 \%$ of test questions to the block are given correct answers). Completion of homework and control tasks was evaluated on a stem scale, for successful completion of the section the participant had to score at least 70 points). The experiment involved 50 teachers of mathematics and school psychologists from different parts of Ukraine, who expressed interest in participating in the pilot project.

Before the training course, we conducted a thorough survey of future participants. The purpose of the diagnosis is to determine the current level of competence of school psychologists and teachers of mathematical disciplines in the theory of giftedness. Analysis of the data showed that most of the subjects have an idea of mathematical talent as a rare phenomenon, but the knowledge is general, vague. Teachers and psychologists are able to distinguish among students mostly bright, explicit mathematical talent, which is not the case with implicit (hidden) or partial talent. A child who demonstrates success exclusively in mathematics and demonstrates a failure in other academic areas, or has a complex character, problems with discipline, most of the teachers surveyed, unfortunately, is not considered gifted. It has become clear that teachers do indeed often confuse giftedness with academic achievement, so a successful student in most school subjects may be mistaken for a gifted student, while a truly mathematically gifted student may be left out of the teacher's attention if he or she does not demonstrate bright overall academic achievement or demonstrate traits of a difficult nature or deviant behavior. Only half of the participants had an idea that the curriculum of a gifted student within a secondary school requires the creation of a separate educational trajectory for him. Respondents had difficulty when asked to create a psychological portrait of a gifted child. School psychologists had an idea of the psychodiagnostic of a mathematically gifted child but sincerely admitted that in practice almost no one had to make such a diagnosis. For many participants in the training program, it was a surprise that nonrecognition of talent or its loss is quite common, not to mention that measures can be taken to prevent these trends. Regarding the specifics of preparing a gifted student to participate in various competitions, contests, and competitions - here theoretical competence of teachers was at a sufficient level, although most noted that they have no experience of such training not just with a strong student, but with a gifted.

After the survey, participants took part in this training project. Assessment of homework and test control in points are presented in Fig. 1.

As you can see, not all participants of the training course were able to score the required minimum number of points in the program. Under the terms of the interactive training program, all participants who scored a GPA of less than 70 were considered not to have met the requirements, and continued to work on the blocks of the program for which they scored less, as certification is possible only if the limit is 70 test scores. 


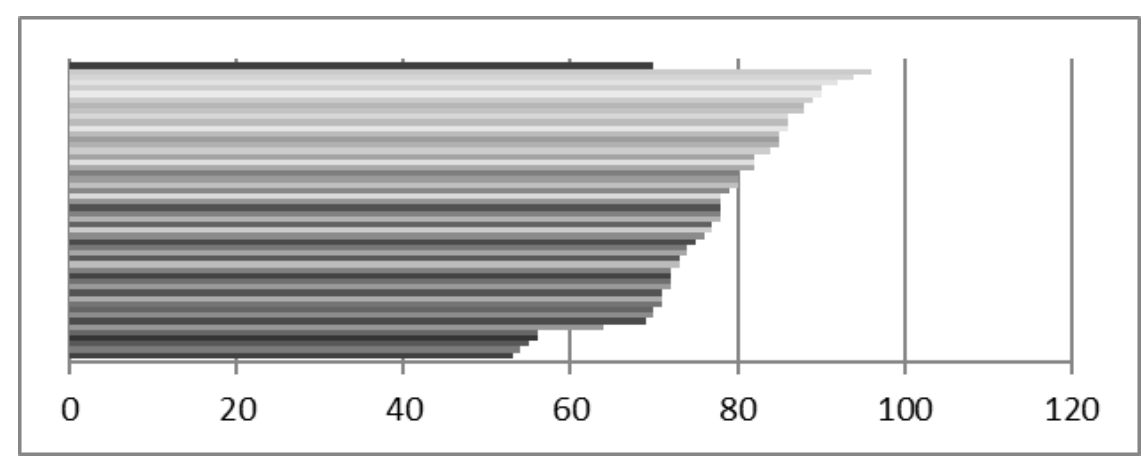

Fig. 1.

After the training, we received feedback from participants, where they shared their impressions. The vast majority of the group (43 educators out of 50) noted that the course helped them to expand their understanding of the essence of talent, its features, markers, areas of practical educational and developmental work with students with a high level of mathematical abilities. Participants shared that information is valuable and necessary for successful work with gifted people, it was very interesting to learn, but this format of training requires planning the necessary time in the daily schedule and a certain level of IT competence.

Conclusions. After conducting an experimental interactive course on the theory of giftedness and current issues of educational and educational work with students with a high level of mathematical abilities, we can note the following. Distance learning is a great addition to traditional methods of professional development and in certain conditions and an alternative that allows the teacher not to interrupt the process of self-development and self-education in the rapidly changing conditions of modern life.

The survey of participants of the initial online course on the theory of giftedness and areas of work with mathematically gifted showed a high level of readiness of teachers to learn through the latest technologies. Thanks to the online training "Psychology of Mathematical Giftedness for Teachers and School Psychologists" we were able to reach teachers and psychologists from different parts of Ukraine, including from small settlements where there are no specialized schools or clubs for children with a high level of mathematical abilities. Thus, the new knowledge gained by these participants in the training program significantly increases the chances of children to discover the potential of mathematical talent, individual approach to their learning and development of abilities.

In our opinion, the construction of a high-quality interactive training course for teachers working with gifted students was successful, but we made a number of conclusions regarding the technology of its construction: the material;

- the main requirement - high-quality lecture video, Internet communication, and content of

- duration of video lectures - no more than 10-15 minutes, so it is possible to carry out the optimal presentation of the material and maintain the appropriate level of attention and interest;

- the convenience of tests for control is necessary;

- a proper level of IT competence is a necessary requirement for participants;

- it is important to have timely contact with the teacher to check and discuss homework.

We believe that this course can be used to improve the skills of subject teachers and / or anyone interested in a deeper understanding of intellectual talent as a mental structure.

\section{REFERENCES}

1. Golovan M.S. (2011). Competence and competence: a comparative analysis of concepts. Pedagogical sciences: theory, history, innovative technologies. 8, 224-233.

2. Dyachenko M.I., Kandybovich L.A., (1978) Psychology of higher school - Minsk: Pub. BSU

3. Ilnitskaya I.L. (2010) Preparation of teachers for the identification and development of gifted children and adolescents. Experience with gifted children in modern Russia: Sat. materials Vseros. scientific-practical conf., M., 188-192.

4. Krutetstkyi B.A., ed. N.I. Chuprykova (1998) Psychology of mathematical abilities of schoolchildren. M.: MPSI Publishing House; Voronezh: MODEK, 416 p.

5. Leiko S.V. (2013) The concept of "competence" and "competences": a theoretical analysis Pedagogy, 8, 128-135

6. N.S. (1996) Leites Psychology of giftedness of children and adolescents. M.

7. Shumakova N.B. (2004) Education and development of gifted children. M.: Publishing house NPO "MODEK".

8. Jung K.G. (1998) The phenomenon of giftedness. Conflicts of the child's soul. - M.

9. Yakovenko T.V. (2012). Distance learning as one of the forms of professional self-development of a teacher. Actual problem of the humanities and natural sciences, 3, 247-249. 